\title{
Effects of recent exposure to a conditioned stimulus on extinction of Pavlovian fear conditioning
}

\author{
Wan Yee Macy Chan, Hiu T. Leung, R. Frederick Westbrook, and Gavan P. McNally ${ }^{1}$
}

School of Psychology, The University of New South Wales, Sydney, New South Wales 2052, Australia

\begin{abstract}
In six experiments we studied the effects of a single re-exposure to a conditioned stimulus (CS; "retrieval trial") prior to extinction training (extinction-reconsolidation boundary) on the development of and recovery from fear extinction. A single retrieval trial prior to extinction training significantly augmented the renewal and reinstatement of extinguished responding. Augmentation of recovery was not observed if the retrieval and extinction training occurred in different contexts. These results contrast with those reported in earlier papers by Monfils and coworkers in rats and by Schiller and coworkers in humans. We suggest that these contrasting results could depend on the contrasting influences of either: (1) occasion-setting contextual associations vs. direct context-CS associations formed as a consequence of the retrieval trial or (2) discrimination vs. generalization between the circumstances of conditioning and extinction.
\end{abstract}

A defining behavioral characteristic of extinction is loss of conditioned responding to the conditioned stimulus (CS) after the breaking of the contingency between the CS and unconditioned stimulus (US) via presentations of the CS alone. This response loss is not permanent. Extinction has several "signature" restoration phenomena (Rescorla 2001; Bouton 2002; Delamater 2004). One signature is spontaneous recovery. When tested shortly after extinction training (e.g., $1 \mathrm{~d}$ ), the extinguished CS elicits little responding, whereas when tested a longer time after extinction training (e.g., 7 d), robust responding is observed (Pavlov 1927; Robbins 1990). A second signature is renewal. Responding to a CS conditioned in one context (context A) and extinguished in a second context (context $\mathrm{B}$ ) is low when tested in the extinction context (i.e., $\mathrm{ABB}$ ) but is high (i.e., is renewed) when tested elsewhere such as the training context (i.e., ABA) (Bouton and Bolles 1979; Harris et al. 2000). A third signature is reinstatement (Pavlov 1927; Rescorla and Heth 1975; Westbrook et al. 2002). Re-presentation of the US after extinction reinstates responding to the CS.

These findings have been interpreted to mean that extinction training does not completely erase the original learning formed during conditioning. Rather, the original learning remains largely intact after extinction training and a mask is imposed on it. This mask is removed with the passage of time, a change in context, or re-presentations of the US and reveals the original learning. This mask is most commonly viewed as the product of new learning during extinction training (Rescorla 2001; Bouton 2002; Delamater 2004). Thus, the dominant view of Pavlovian extinction states that whereas conditioning results in the formation of a CS-US association, extinction promotes formation of a new association. This association has been variously described as a CS-No US association, an inhibitory CS-US association, or an inhibitory CS-conditioned response (CR) association. Regardless, after extinction training, subjects hold conflicting associations regarding the CS: a CS-US association causing fear expression and an association from extinction training causing fear inhibition. Which of these associations is retrieved to generate performance on a test depends, at least in part, on the context where the test occurs, with the extinction association being

'Corresponding author.

E-mail g.mcnally@unsw.edu.au; fax 61-2-93853044.

Article is online at http://www.learnmem.org/cgi/doi/10.1101/lm.1912510. particularly dependent on the accompanying contextual cues for retrieval (Bouton 1993). These contextual cues can be physical (e.g., conditioning apparatus), temporal, or internal (e.g., hormonal state). When there is congruence between the extinction contextual cues and the test cues, responding is low. When these cues are incongruent, responding is restored or recovered (Bouton 1993). According to this view, contexts are critical in promoting and regulating the expression of extinction learning because they set the occasion for nonreinforcement of the CS.

This dominant "new learning" view of extinction receives strong support from a variety of conditioning preparations across a variety of species, including mouse, rabbit, rat, and humans (for reviews, see Bouton 2002; Delamater 2004). These restoration phenomena are also shared with other procedures that produce decrements in conditioned responding, such as overexpectation (Rescorla 2006a; Garfield and McNally 2009) and US habituation (Storsve et al. 2010). This strongly suggests that restoration or relapse is a common consequence of most procedures that are designed to reduce conditioned responding and produce behavioral change.

Given the important role for extinction in the loss of learned fear responses, its status as a core mechanism for behavioral change in therapeutic approaches to treating human anxiety, and the overwhelming evidence that the original fear association survives extinction training largely intact, considerable effort has been dedicated to developing novel behavioral approaches to enhance extinction learning. These approaches include, but are not limited to, extinction in multiple contexts (Gunther et al. 1998; Chelonis et al. 1999), augmentation of prediction error during extinction learning and/or extinction of multiple CSs in compound (e.g., Rescorla 2006b; Leung and Westbrook 2008; Urcelay et al. 2009), and extinction shortly after conditioning (Myers et al. 2006). However, in many of these cases, augmentation of extinction is parameter dependent. For example, the amount of initial fear learning may determine whether extinction shortly after conditioning augments or impairs extinction learning (Maren and Chang 2006). Likewise, the augmentation of extinction learning by extinguishing multiple CSs in compounds depends specifically on procedures that reduce generalization decrements from extinction to testing (Urcelay et al. 2009) and that control for differences in CS salience (Rescorla 2006b). These caveats do not reduce the theoretical and practical significance of manipulations that augment extinction, but rather they underscore the robustness 
of the response recovery following extinction, and they emphasize that the effects of these manipulations may be apparent only under restricted conditions.

Recently, Monfils et al. (2009) used an approach similar to that of Myers et al. (2006) to modify extinction training and cause fear response loss that was not subject to restoration and relapse. Rats were trained to fear an auditory CS via pairings with footshock. The following day, rats received a single nonreinforced exposure to the CS (a reminder trial) or they received no such reminder. Extinction training commenced shortly (10 min to $1 \mathrm{~h})$ after this reminder exposure. There were no differences between groups during extinction training or on tests for longterm retention of extinction learning. However, rats that received extinction training without the reminder exposure to the CS developed fear extinction that was subject to renewal, reinstatement, and spontaneous recovery. In contrast, rats that received extinction training after the reminder exposure to the CS developed fear extinction that was not subject to these restoration effects. Schiller et al. (2010) reported the same phenomenon in human electrodermal conditioning. In the critical experiment, human participants received training so that CSA was paired with shock, CSB was paired with shock, and CSC was never paired with shock. The participants then received a reminder, nonreinforced presentation of CSA. They then underwent extinction training of CSA and CSB. The fear responses to CSB (the nonretrieved CS) could be restored via reinstatement, whereas fear responses to CSA (the retrieved CS) could not.

Taken together, these findings by Monfils et al. (2009) and Schiller et al. (2010) suggest that the recent retrieval of a fear memory is able to alter the nature of fear extinction learning. Interestingly, this was not observed as altered responding during either fear extinction training or test. Rather, it was specifically limited to the absence of fear recovery. These findings have been interpreted to mean that a single re-exposure to the CS renders the original fear memory labile. Extinction training that occurs within this lability window may destabilize the original fear memory, causing it to be lost or permanently altered. The aim of these experiments was to use the "retrieval-extinction" procedure described by Monfils et al. (2009) and Schiller et al. (2010) to study the effects of recent exposures to the CS on the extinction and recovery of conditioned responding via renewal and reinstatement in Pavlovian fear conditioning.

\section{Results}

\section{Experiment 1}

Experiment 1 attempted to replicate the finding reported by Monfils et al. (2009) that an isolated retrieval trial (a single nonreinforced CS presentation) $1 \mathrm{~h}$ prior to a bout of extinction prevented the renewal of responding compared to a group with mere context exposure prior to extinction. Monfils et al. (2009) reported that this retrievalextinction manipulation prevented the context-dependent renewal of fear to an auditory CS that was trained in context $\mathrm{A}$ and was extinguished in context $\mathrm{B}$ and subsequently tested in context A. The experiment employed a similar twogroup design and procedure to that of Monfils et al. (2009). Groups Retrieval (Ret) and No Retrieval (No Ret) were trained to fear an auditory CS via pairings with a footshock US in context A. This fear was then extinguished in context B prior to the test for fear responses to the CS in the extinction context, context $\mathrm{B}$, and the training context, context $\mathrm{A}$. The groups differed only in the nature of their experiences $90 \mathrm{~min}$ prior to extinction training. Group Retrieval was placed in the extinction context at this time and received a single nonreinforced exposure to the CS. Group No Retrieval was likewise placed in the extinction context, but no stimulus events were scheduled.

The mean $( \pm$ SEM) percentage of observations scored as freezing across the experiment is shown in Figure 1. Inspection of the figure suggests that the presentation of a single CS prior to a bout of extinction training did not affect the expression of freezing during extinction training and also did not affect the development of long-term extinction in the extinction context (context B) as indexed by freezing to the CS on the test. However, this retrieval trial prior to extinction resulted in the stronger recovery of freezing responses when animals were returned to the acquisition context compared with those that merely received exposure to the context prior to extinction. These observations were confirmed by the statistical analysis.

During acquisition, levels of pre-CS freezing were low (mean $=1$, SEM $=1)$. A within-subjects analysis showed that fear to the CS was acquired normally because freezing increased across CS-US pairings, $F_{(1,15)}=102.4, P<0.05$. During retrieval, there was no difference between groups in freezing during the 3 -min pre-CS period (group Ret mean $=9, \mathrm{SEM}=4$; group No Ret mean $=7, \mathrm{SEM}=1), F_{(1,15)}<1, P>0.05$. Group Ret displayed significantly more freezing during the single CS presentation compared with the pre-CS period, $F_{(1,7)}=177.4, P<0.05$.

During extinction, there was no significant difference in the level of pre-CS freezing between group Ret $($ mean $=18, \mathrm{SEM}=7$ ) and group No Ret $($ mean $=4, \mathrm{SEM}=2), F_{(1,14)}=3.2, P>0.05$. The average level of freezing across the extinction CS presentations (averaged across the 18 or first 18 for group Ret and No Ret, respectively) did not differ between the two groups, $F_{(1,14)}<1, P>0.05$. Averaged across groups, there was evidence for within-session extinction because freezing decreased in a significant linear fashion across CS presentations, $F_{(1,14)}=55.0, P<0.05$. This withinsession extinction did not interact with the retrieval factor, such that the decrease in freezing was comparable for group Ret and group No Ret, $F_{(1,14)}<1, P>0.05$.

The data from tests are shown in the right-hand panel of Figure 1 . There were no significant differences between groups in levels of pre-CS freezing in context B (group Ret mean $=0$, $\mathrm{SEM}=0$; group No Ret mean $=0, \mathrm{SEM}=0$ ) or context A (group Ret mean $=17, \mathrm{SEM}=5$; group No Ret mean $=13, \operatorname{SEM}=4)$, $F \mathbf{s}_{(1,14)}<1, P>0.05$. Averaged across groups, there was a significant overall renewal effect, $F_{(1,14)}=56.9, P<0.05$. There was, overall, significantly more freezing in group Ret than group No Ret, $F_{(1,14)}=5.7, P<0.05$. The context $\times$ group interaction was narrowly nonsignificant, $F_{(1,14)}=4.4, P=0.054$.

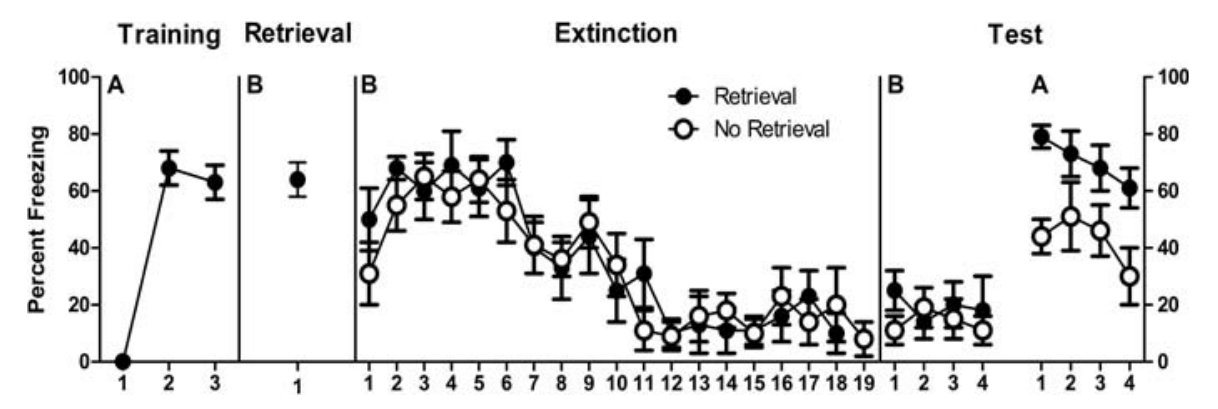

Figure 1. Mean and SEM levels of freezing across the four stages of Experiment 1. Retrieval 90 min prior to extinction augmented ABA renewal of extinguished fear. 
There was no significant difference between groups in freezing during test presentations of the CS in context $\mathrm{B}$, $F_{(1,14)}<1, P>0.05$. There was no significant decrease in freezing across test presentations in context $\mathrm{B}, F_{(1,14)}<1, P>$ 0.05 , and there was no group $\times$ trial interaction during the test in context $\mathrm{B}$, $F_{(1,14)}<1, P>0.05$. There were significant differences between groups during test presentations of the CS in context A, so that group Ret displayed significantly more freezing than did group No Ret, averaged across CS presentations, $F_{(1,14)}=8.9, P<0.05$. There was a significant decrease in freezing across CS presentations on the test in context $\mathrm{A}$, $F_{(1,14)}=5.5, P<0.05$, but there was no group $\times$ trial interaction during the test in context $\mathrm{A}, F_{(1,14)}<1, P>0.05$.

\section{Experiments $2 \mathrm{~A}$ and $2 \mathrm{~B}$}

The results from Experiment 1 show that regardless of whether extinction training was preceded or not by a single nonreinforced exposure to the CS, the extinction of Pavlovian fear conditioning is context specific. When rats were tested in the extinction context, fear responses to the extinguished CS were low; whereas when tested in the training context, fear responses to the extinguished CS were renewed (Bouton and Bolles 1979). Surprisingly, the results did not replicate those reported by Monfils et al. (2009). In fact, in contrast to Monfils et al. (2009), the results showed augmented renewal of responding to the extinguished CS in rats that received a single nonreinforced presentation of the CS prior to the extinction training. According to the reconsolidation interpretation, reexposure to the CS renders the original fear memory labile. Extinction training that occurs within this lability window destabilizes the original fear memory, causing it to be resistant to later restoration. It is possible that the re-exposure in Experiment 1 did not sufficiently reactivate the original training memory and therefore did not allow extinction to destabilize the original fear memory. One approach to strengthening the retrieval of the original training memory is to increase the similarity between training and retrieval. Therefore, we used the same design in these experiments as was used for Experiment 1 but re-exposed rats to the CS in the original training context (Experiment 2A) prior to extinction in a second context or re-exposed rats to the CS in the tobe-extinction context (Experiment 2B) prior to extinction in that context.

\section{Experiment $2 A$}

The mean ( \pm SEM) percentages of observations scored as freezing across the experiment are shown in the top panels of Figure 2. During acquisition, levels of pre-CS freezing were low (mean = 3, SEM =1). A within-subjects analysis showed that fear to the CS was acquired normally because freezing increased across CS-US pairings, $F_{(1,15)}=44.3, P<0.05$. During retrieval, there was no difference between groups in freezing during the 3-min pre-CS period (group Ret mean $=44, \mathrm{SEM}=10$; group No Ret mean $=44$, SEM $=8), F_{(1,14)}<1, P>0.05$. Group Ret displayed significantly more freezing during the single CS presentation compared with the pre-CS period, $F_{(1,7)}=8.4, P<0.05$.
During extinction, there was no significant difference in the level of pre-CS freezing between group Ret (mean $=4, \mathrm{SEM}=2$ ) and group No Ret $($ mean $=1, \mathrm{SEM}=1), F_{(1,14)}=1.4, P>0.05$. The average level of freezing across the extinction CS presentations (averaged across the 18 or first 18 for groups Ret and No Ret, respectively) did not differ between the two groups, $F_{(1,14)}=$ $1.1, P>0.05$. Averaged across groups, there was evidence for within-session extinction because freezing decreased in a significant linear fashion across CS presentations, $F_{(1,14)}=87.1, P<$ 0.05 . This within-session extinction did not interact with the retrieval factor, such that the decrease in freezing was comparable for group Ret and group No Ret, $F_{(1,14)}=2.8, P>0.05$.

The data from test are shown in the top right-hand panel of Figure 2. There were no significant differences between groups in levels of pre-CS freezing in context B (group Ret mean $=1, \mathrm{SEM}=$ 1 ; group No Ret mean $=0, \mathrm{SEM}=0$ ) or context A (group Ret mean $=15$, SEM $=6$; group No Ret mean $=16$, SEM $=7$ ) $F s_{(1,14)} \leq 1, P>0.05$. Averaged across groups, there was a significant overall renewal effect, $F_{(1,14)}=6.2, P<0.05$. There was no overall difference in freezing in group Ret vs. group No Ret, $F_{(1,14)}=1.7, P>0.05$. The context $\times$ group interaction was nonsignificant, $F_{(1,14)}=1.5, P>0.05$.

There was no overall significant difference between groups in freezing during test presentations of the CS in context $\mathrm{B}, F_{(1,14)}=$ $3.5, P>0.05$. There was no significant decrease in freezing across test trials in context $\mathrm{B}, F_{(1,14)}<1, P>0.05$, and no group $\times$ test trial interaction, $F_{(1,14)}<1, P>0.05$. However, group Ret did display significantly less freezing to the CS on the first test presentation in context B than did group No Ret, $F_{(1,14)}=5.3, P<0.05$.

There was no overall significant difference between groups in freezing during test presentations of the CS in context A, $F_{(1,14)}<$ $1, P>0.05$. There was no overall significant decrease in freezing across test presentations in context $\mathrm{A}, F_{(1,14)}<1, P>0.05$, but there was a group $\times$ trial interaction on test in context $\mathrm{A}$, $F_{(1,14)}=6.9, P<0.05$, indicating that freezing decreased more across test trials in group Ret than group No Ret. This more rapid 
extinction of renewed fear could be indicative of weaker renewal in group Ret, but there were no differences between groups on individual test presentations of the CS in context A.

\section{Experiment $2 B$}

The mean $( \pm$ SEM) percentages of observations scored as freezing across the experiment are shown in the bottom panels of Figure 2. During acquisition, levels of pre-CS freezing were low (mean $=0$, SEM $=0$ ). A within-subjects analysis showed that fear to the CS was acquired normally because freezing increased across CS-US pairings, $F_{(1,15)}=42.0, P<0.05$. During retrieval, there was no difference between groups in freezing during the 3-min pre-CS period (group Ret mean $=1, \mathrm{SEM}=1$; group No Ret mean $=1$, SEM = 1), $F_{(1,14)}<1, P>0.05$. Group Ret displayed significantly more freezing during the single CS presentation compared with the pre-CS period, $F_{(1,7)}=308.9, P<0.05$.

During extinction, there was no significant difference in the level of pre-CS freezing between group Ret (mean $=1, \mathrm{SEM}=1)$ and group No Ret (mean $=0, \mathrm{SEM}=0), F_{(1,14)}<1, P>0.05$. The average level of freezing across the extinction CS presentations (across the 18 or first 18 for group Ret and No Ret, respectively) did differ between the two groups, $F_{(1,14)}=9.4, P<0.05$, so that there was significantly less freezing in group Ret. Averaged across groups, there was evidence for within-session extinction because freezing decreased in a significant linear fashion across CS presentations, $F_{(1,14)}=61.1, P<0.05$. This within-session extinction did interact with the retrieval factor, such that the decrease in freezing was greater for group Ret than group No Ret, $F_{(1,14)}=21.7, P<0.05$.

The data from tests are shown in the bottom right-hand panel of Figure 2. There were no significant differences between groups in levels of pre-CS freezing in context B (group Ret mean $=0, \mathrm{SEM}=0$; group No Ret mean $=0, \mathrm{SEM}=0$ ) or context A (group Ret mean $=22, \mathrm{SEM}=8$; group No Ret mean $=18$, $\mathrm{SEM}=5) \quad F \mathrm{~s}_{(1,14)}<1, P>0.05$. Averaged across groups, there was a significant overall renewal effect, $F_{(1,14)}=28.7, P<0.05$. There was no overall difference in freezing in group Ret vs. group No Ret, $F_{(1,14)}=2.7, P>0.05$. The context $\times$ group interaction was significant, $F_{(1,14)}=14.4, P<0.05$.

There was no overall significant difference between groups in freezing during test presentations of the $\mathrm{CS}$ in context $\mathrm{B}, F_{(1,14)}=$ 1.6, $P>0.05$. There was also no significant decrease in freezing across test presentations in context $\mathrm{B}, F_{(1,14)}<1, P>0.05$, nor a group $\times$ trial interaction during test in context $\mathrm{B}, F_{(1,14)}<1, P>$ 0.05 . There was an overall significant difference between groups in freezing during test presentations of the CS in context A, so that group Ret displayed significantly more freezing than group No Ret, $F_{(1,14)}=24.1, P<0.05$. There was no overall significant decrease in freezing across test presentations in context A, $F_{(1,14)}<1, P>0.05$, and there was no group $\times$ trial interaction on test in context $\mathrm{A}, F_{(1,14)}<1, P>0.05$. These experiments have shown contrasting effects of a memory retrieval trial occurring in the training or extinction context. Retrieval in the training context produced a modest reduction in responding to the CS on a test in the extinction context, whereas retrieval in the extinction context augmented responding to the CS on a test in the training context.

\section{Experiment 3}

The interval between re-exposure to the CS and extinction training may be a critical determinant of the effects of re-exposure on extinction learning. Monfils et al. (2009) used a 1-h interval between nonreinforced exposure to the CS and extinction training to study the impact on renewal, whereas the experiments reported here used a 90-min interval. Although this 90-min period is within the window of reconsolidation as defined by Monfils et al. (2009), it is possible that reconsolidation manipulations may be most effective when administered shortly after retrieval. For example, if a reactivated memory restabilizes with time, more proximal extinction training following the retrieval may allow stronger modulation of the original fear memory. Indeed, Monfils et al. (2009) reported that a 10-min interval between retrieval and extinction interval prevented the later spontaneous recovery of extinguished fear. Therefore, in Experiment 3 we employed the same two-group design as in previous experiments, but there was a 10-min interval between the retrieval trial in the extinction context and the start of extinction training.

The mean $( \pm$ SEM) percentages of observations scored as freezing across the experiment are shown in Figure 3. During acquisition, levels of pre-CS freezing were low (mean $=0, \mathrm{SEM}=$ $0)$. A within-subjects analysis showed that fear to the CS was acquired normally because freezing increased across CS-US pairings, $F_{(1,15)}=60.2, P<0.05$. During retrieval, there was no difference between groups in freezing during the 3-min pre-CS period (group Ret mean $=3, \mathrm{SEM}=2$; group No Ret mean $=3, \mathrm{SEM}=$ $1), F_{(1,15)}<1, P>0.05$. Group Ret displayed significantly more freezing during the single CS presentation compared with the pre-CS period, $F_{(1,7)}=109.7, P<0.05$.

During extinction, there was no significant difference in the level of pre-CS freezing between group Ret (mean $=42, \mathrm{SEM}=8$ ) and group No Ret $($ mean $=26, \operatorname{SEM}=7), F_{(1,14)}=2.1, P>0.05$. The level of freezing across the extinction CS presentations (averaged across the 18 or first 18 for group Ret and No Ret, respectively) differed significantly between the two groups, $F_{(1,14)}=$ $5.0, P<0.05$, so that group Ret showed significantly more freezing than did group No Ret. Averaged across groups, there was evidence for within-session extinction because freezing decreased in a significant linear fashion across CS presentations, $F_{(1,14)}=111.4$, $P<0.05$. This within-session extinction did not interact with the retrieval factor, such that the decrease in freezing was comparable for group Ret and group No Ret, $F_{(1,14)}<1, P>0.05$.

The data from tests are shown in the right-hand panel of Figure 3. There were no significant differences between groups in levels of pre-CS freezing in context B (group Ret mean $=0$, $\mathrm{SEM}=0$; group No Ret mean $=1, \mathrm{SEM}=1$ ) or context A (group Ret mean $=21, \operatorname{SEM}=7$; group No Ret mean $=35, \operatorname{SEM}=9$ ), $F \mathrm{~s}_{(1,14)}<2.3, P>0.05$. Averaged across groups, there was a significant overall renewal effect, $F_{(1,14)}=48.8, P<0.05$. There was no overall difference in freezing between group Ret and group No Ret, $F_{(1,14)}=1.6, P>0.05$. There was no context $\times$ group interaction, $F_{(1,14)}<1, P>0.05$.

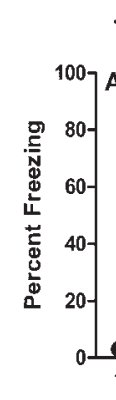

Training Retrieval

Extinction

Figure 3. Mean and SEM levels of freezing across the four stages of Experiment 3. Retrieval 10 min prior to extinction increased freezing during extinction and tests in context B and context $A$. 
There was no overall significant difference between groups in freezing during test in context $\mathrm{B}, F_{(1,14)}=1.9, P>0.05$. However, there was a significant overall decrease in freezing across test trials in context $\mathrm{B}, F_{(1,14)}=4.8, P<0.05$, and there was a group $\times$ test trial interaction during test in context $\mathrm{B}, F_{(1,14)}=5.4, P<0.05$. This interaction shows that differences between groups were significantly greater at the start than at the end of the test session in context B. Follow-up analyses confirmed that group Ret showed significantly more freezing than did group No Ret averaged across the first two CS presentations in context B, $F_{(1,14)}=7.8, P<0.05$.

There was no overall significant difference between groups in freezing during test in context $\mathrm{A}, F_{(1,14)}<1, P>0.05$. There was no overall significant decrease in freezing across test trials in context A, $F_{(1,14)}=1.8, P>0.05$. However, there was a group $\times$ trial interaction during test in context $\mathrm{A}, F_{(1,14)}=8.9, P<0.05$, showing that differences between groups were significantly greater at the start than at the end of the test session in context A. Follow-up analyses confirmed that group Ret showed significantly more freezing than did group No Ret only during the first CS presentation in context A, $F_{(1,14)}=7.0, P<0.05$.

\section{Experiments $4 \mathrm{~A}$ and $4 \mathrm{~B}$}

The results thus far suggest that under present conditions a single, nonreinforced exposure to a fear CS augments fear renewal if that exposure occurs in the extinction context. Monfils et al. (2009) and Schiller et al. (2010) also reported that exposure to a CS prior to extinction training reduced the recovery of extinguished fear via reinstatement. The aim of the present experiments was to study how such exposure affects reinstatement of extinguished responding. We adopted two approaches to address this aim. In Experiment 4A, we used a between-groups design similar to that used by Monfils et al. (2009). Thus, groups Retrieval and No Retrieval were trained, extinguished, reinstated, and tested. They differed only in whether they received a single nonreinforced exposure to the CS or not $10 \mathrm{~min}$ prior to extinction training. In Experiment 4B, we used a within-subjects design. Thus, fear to a tone CS and a flashing light CS was trained, extinguished, reinstated, and tested. The CSs differed only in whether one had been exposed $10 \mathrm{~min}$ prior to extinction training or not. This withinsubjects design is similar to that used by Schiller et al. (2010). For present purposes, the primary advantages of the design are that it controls for the differences in CS and context exposure inherent in the between-groups designs used previously and that it provides greater statistical power for detecting an effect of retrieval.

\section{Experiment $4 A$}

The mean ( \pm SEM) percentages of observations scored as freezing across the four stages of the experiment are shown in the top panels of Figure 4. During acquisition, levels of pre-CS freezing were low $($ mean $=0, \mathrm{SEM}=0)$. A within-subjects analysis showed that fear to the CS was acquired normally because freezing increased linearly across CS-US pairings, $F_{(1,15)}=65.6, P<0.05$. During retrieval, there was no difference between groups in freezing during the 3-min pre-CS period (group Ret mean $=4$, $\operatorname{SEM}=1$; group No Ret mean $=7, \operatorname{SEM}=3), F_{(1,15)}=1.1, P>$ 0.05 . Group Ret displayed significantly more freezing during the single CS presentation compared with the pre-CS period, $F_{(1,7)}=$ 64.9, $P<0.05$.

During extinction, there was no significant difference in the level of pre-CS freezing between group Ret (mean $=12, \mathrm{SEM}=5$ ) and group No Ret $($ mean $=10, \mathrm{SEM}=5), F_{(1,14)}<1, P>0.05$. The level of freezing across the extinction CS presentations (averaged across the 18 or first 18 for group Ret and No Ret, respectively) did not differ significantly between the two groups, $F_{(1,14)}<1, P>0.05$. Averaged across groups, there was evidence for within-session extinction because freezing decreased in a significant linear fashion across CS presentations, $F_{(1,14)}=26.6$, $P<0.05$. This within-session extinction did not interact with the retrieval factor, such that the decrease in freezing was comparable for group Ret and group No Ret, $F_{(1,14)}<1, P>0.05$.

The data from tests are shown in the top right-hand panel of Figure 4 . There were no significant differences between groups in levels of pre-CS freezing (group Ret mean $=45, \mathrm{SEM}=9$; group No Ret mean $=37$, SEM = 11), $F_{(1,14)}<2.3, P>0.05$. Averaged across groups, there was a reinstatement effect so that freezing was significantly greater across the test presentations of the CS compared with the last four CS presentations during extinction, $F_{(1,14)}=21.1, P<0.05$. However, there was no overall difference in freezing between group Ret and group No Ret on test, $F_{(1,14)}<1, P>0.05$, nor a significant interaction between groups and the increase in freezing from extinction to test, $F_{(1,14)}\langle 1, P\rangle$ 0.05 . There was no significant decrease in freezing across CS presentations on test, $F_{(1,14)}=3.3, P>0.05$, and there was no group $\times$ trial interaction on test, $F_{(1,14)}<1, P>0.05$.

\section{Experiment $4 B$}

The mean $( \pm$ SEM) percentages of observations scored as freezing during retrieval, extinction, and test are shown in the bottom

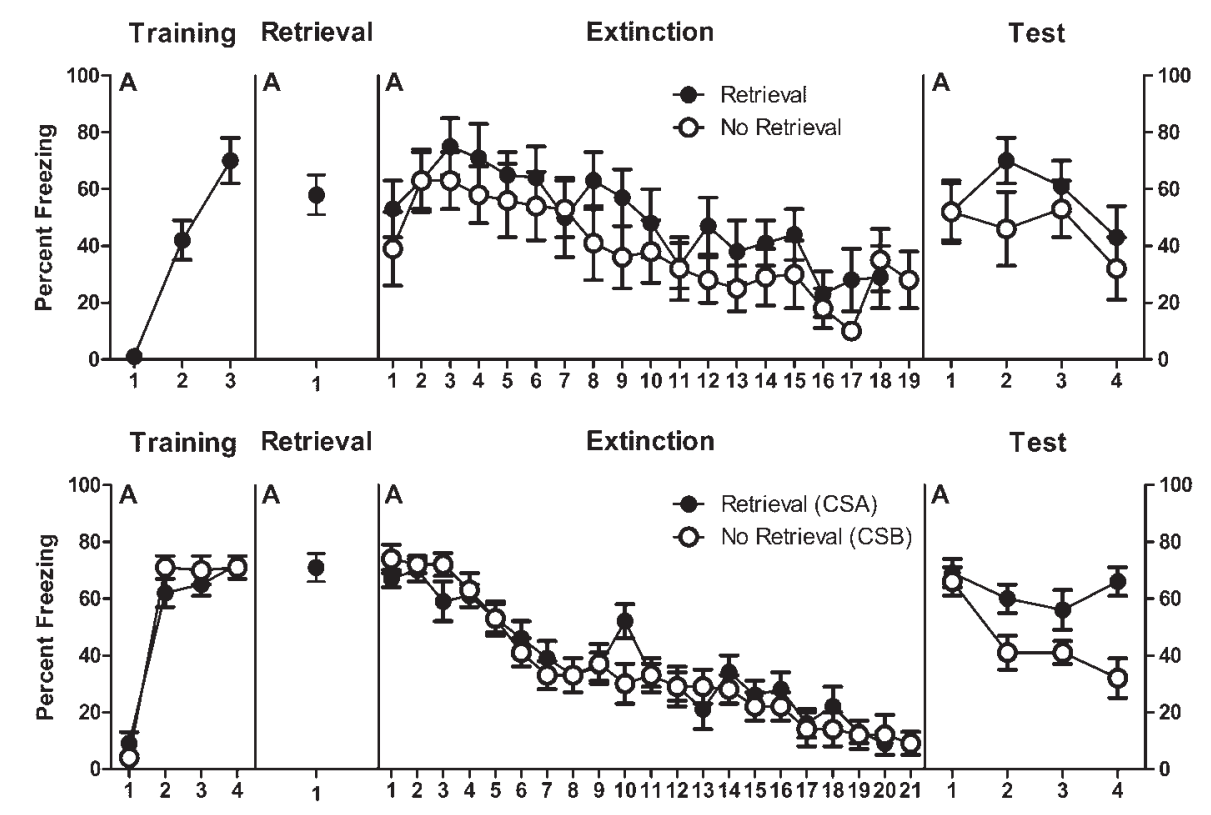

Figure 4. Mean and SEM levels of freezing across the four stages of Experiment 4A (top panels) and Experiment 4B (bottom panels). Retrieval $10 \mathrm{~min}$ prior to extinction had no significant effect on reinstatement in Experiment $4 \mathrm{~A}$ (between-subjects reinstatement) but significantly increased reinstatement in Experiment 4B (within-subjects reinstatement). 
panels of Figure 4. During acquisition, levels of pre-CS freezing were low (mean pre-CSA $=5, \operatorname{SEM}=3.1$; mean pre-CSB $=1.9$, SEM $=1.2$ ). A within-subjects analysis showed that fear to the CSs was acquired normally because freezing increased linearly across CS-US pairings, $F_{(1,11)}=219.7, P<0.05$. There was no overall difference in freezing to CSA or CSB during acquisition, $F_{(1,11)}<1, P>0.05$, and no $\mathrm{CS} \times$ trial interaction, $F_{(1,11)}<1$, $P>0.05$. During retrieval, there was significantly more freezing to CSA than during the 2-min pre-CSA period (mean=23; SEM = 7), $F_{(1,11)}=76.1, P<0.05$. During extinction training, there were low levels of freezing in the 2-min pre-CS period (mean $=15, \mathrm{SEM}=3$ ). There was no overall significant difference in freezing to CSA (the CS that had been exposed) and CSB (the CS that had not been exposed), $F_{(1,11)}=3.0, P>0.05$. Averaged across CSs, there was evidence for within-session extinction because freezing decreased in a significant linear fashion across CS presentations, $F_{(1,11)}=241.5, P<0.05$. There was no difference between CSs in this extinction, $F_{(1,11)}=1.6, P>0.05$.

The data from test are shown in the bottom right-hand panel of Figure 4 . There was reinstatement because there was significantly more freezing on test than during the last four extinction trials, $F_{(1,12)}=88.5, P<0.05$. There was an overall difference in freezing to CSA and CSB-there was significantly more freezing to CSA (the CS exposed prior to extinction) than CSB (the CS not exposed prior to extinction), $F_{(1,12)}=15.3, P<0.05$, averaged across the last four extinction trials and the four test trials. There was a significant linear decrease in freezing across test trials, $F_{(1,11)}=10.2, P<0.05$. Finally, there was a CS $\times$ test trial interaction, $F_{(1,11)}=9.7, P<0.05$, indicating less reduction of responding to CSA than CSB. Together, these results show augmented reinstatement of fear to the retrieval CS, CSA.

\section{Discussion}

These experiments studied the effects of a recent, nonreinforced exposure to a CS on the extinction of conditioned responding to that CS as well as the recovery of responding to that CS after extinction training. There are three primary findings. The first is that a brief, nonreinforced exposure to a CS prior to fear extinction training increased responding to that CS on subsequent tests for renewal (Experiments 1, 2B, and 3) and reinstatement (Experiment 4B). The second finding is that these exposures had inconsistent effects on within-session performance during extinction. Freezing was decreased (Experiment 2B), increased (Experiment 3), and unaffected (Experiments 1, 2A, and 4B) by recent CS exposure. Finally, in contrast to the findings of Monfils et al. (2009) in rats and Schiller et al. (2010) in humans, there was little evidence that a single nonreinforced exposure to the CS shortly prior to extinction training attenuated the later recovery of extinguished responding. The results of Experiment $2 \mathrm{~A}$, when retrieval occurred in the conditioning context, were most consistent with this possibility. In this experiment, extinction after retrieval reduced freezing on test, but this reduction was observed only in the extinction context. That is, the retrieval manipulation did not weaken renewal; instead it deepened extinction when assessed in the extinction context. Our failures to detect weakened fear renewal and reinstatement are not easily attributable to the use of insensitive measures because in each experiment we could show the acquisition, retrieval, extinction, as well as recovery of responding, and we typically found that exposure to the CS prior to extinction augmented the recovery, which is opposite to that reported by Monfils et al. (2009) and Schiller et al. (2010).

Monfils et al. (2009) as well as Schiller et al. (2010) argued that re-exposure to a fear CS during a retrieval trial renders the original fear memory labile. Extinction training that occurs within this lability window destabilizes the original fear memory, causing it to be resistant to restoration. The nature of this destabilization is unclear but was suggested to potentially involve a permanent change or loss of the valence originally conferred on the CS during fear conditioning. It is not immediately clear whether such a mechanism could explain the opposing effects of CS retrieval reported in the present experiments. Specifically, it is unclear how re-exposure to the CS can either augment or impair the later renewal and reinstatement of extinguished fear or why the effects of this re-exposure depended on whether extinction was conducted in the same or different context to that of retrieval.

It is possible that procedural differences between our experiments and those reported by Monfils et al. (2009) are critical for whether impaired or augmented recovery of extinguished responding is detected. These experiments used similar procedures, temporal intervals, and measures of fear to those used by Monfils et al. (2009). Indeed, prior to test for recovery, the performances of the animals in these experiments and those reported by Monfils et al. (2009) were similar. There are three potentially important procedural differences. First, Monfils et al. (2009) used a $5-\mathrm{kHz}$ tone $\mathrm{CS}$, whereas these experiments used 750- to $-1200-\mathrm{Hz}$ tone CSs. Although these CSs resulted in similar levels of responding during retrieval and extinction, the precise physical characteristics of the CS involved may determine the mechanisms recruited. However, the finding by Schiller et al. (2010) of similar effects under vastly different conditions in studies of human aversive learning strongly suggests that subtle differences in stimulus parameters or behavioral manipulations are insufficient to explain our contrasting findings. Second, in their studies on renewal, Monfils et al. (2009) used the same experimental chambers to create separate conditioning vs. extinction contexts, whereas we used different chambers located in different laboratories for conditioning and extinction. This difference may be important for understanding the results from renewal experiments but is difficult to apply to reinstatement experiments that used a single context. Finally, in the experiments reported here (with the exception of Experiment 4A), we relied on a common test to make inferences about the magnitude of recovery of conditioned responding. In contrast, Monfils et al. (2009) as well as Schiller et al. (2010) typically relied on comparisons between performances at the end of extinction training and performances on a test to make inferences regarding recovery of the fear response. Although comparisons between extinction and test performances are statistically more powerful, they can be problematic because they involve comparisons of performances at different points in time. The importance of this difference to understanding the differences between the results of Monfils et al. (2009) and the results reported here is unclear. There was only minimal evidence here that the retrieval group showed less conditioned responding than did the no retrieval group (Experiment 2A). Instead, the opposite pattern of results was more frequently observed.

It is worth considering whether other accounts could apply equally well to the data reported here and those reported by Monfils et al. (2009) as well as Schiller et al. (2010). We will consider two such accounts. The first emphasizes the role of learning during the CS re-exposure in group Retrieval. Under the conditions of the present experiments, animals learn at least two different things about the contextual cues accompanying presentations of the CS during the retrieval trial. First, they learn that the context sets the occasion for nonreinforcement of the CS. This hierarchical association promotes the development of extinction to the CS in the subsequent extinction session because it effectively constitutes an initial extinction episode. Second, they learn a context-CS association. This association has a detrimental influence on extinction learning and performance in the retrieval context. 
The formation of a context-CS association during the retrieval phase of the experiment primes the CS so that it is expected during extinction training in the retrieval context, and consequently, less extinction learning accrues to that expected CS (Wagner 1976, 1981). However, this impaired extinction is not expressed on testing in the extinction context because the context-CS association again primes and so reduces responding to the CS on testing in that context. This impaired extinction learning is expressed outside the extinction context such as during renewal. Formation of a context-CS association also explains an augmented reinstatement because such associations are responsible for reinstatement (Westbrook et al. 2002). It follows that manipulations that reduce any influence of the context-CS association formed during the retrieval phase on subsequent extinction learning should prevent the impaired extinction/augmented recovery effects. The results of Experiment 2A showed precisely this: When retrieval occurred in a context different to that used for extinction, retrieval did not disrupt extinction and, in fact, produced the only evidence that it may have augmented extinction. Therefore the consequence of exposures to the CS prior to extinction may depend on the relative strengths of these occasion setting vs. context CS two associations.

A second account invokes learning about the difference between conditioning and extinction. Capaldi (1966) emphasized the signaling properties of reinforcement and nonreinforcement in discrimination between acquisition and extinction. Redish et al. (2007) have extended this line of reasoning. They propose that during conditioning, animals acquire associations on the basis of an error-correcting learning rule and that they also classify the experimental situation into a specific "state," "a representative collection of salient observations." Nonreinforcement of the CS during extinction has two distinct consequences. First, unlearning occurs. Second, the animals split or re-represent the original state as a new state ("extinction"). The consequence of state-splitting is that the remaining fear of the $\mathrm{CS}$ is preserved. The amount of fear preserved depends on when state-splitting occurs. If the state-splitting is delayed or does not occur, little if any of the original fear of the CS is preserved. In contrast, if the state-splitting occurs precociously or rapidly, then much of the original fear of the CS is preserved. The similarity of the training and extinction contexts is critical for the timing of state-splitting. The more dissimilar these contexts are, the greater the probability of state-splitting. The differences between our results and those reported by Monfils et al. (2009) could be due to whether animals reclassify the cues accompanying extinction training into a new state, causing the preservation of the original association and hence greater renewal and reinstatement, or whether animals do not reclassify these cues into a new state, causing the unlearning of the original association and hence weaker renewal and reinstatement. As noted above, Monfils et al. (2009) used the same experimental chambers to create separate conditioning vs. extinction contexts, whereas we used different chambers located in different laboratories. These differences could promote different amounts of discrimination or statespitting between conditioning and extinction. This model could also explain the opposing effects on renewal of using the conditioning or extinction context for the retrieval trial in Experiments 2, A and B. When retrieval occurred in the same context as conditioning there was some, albeit weak, evidence for deeper extinction (i.e., no state splitting or more generalization). When retrieval occurred in the different (to-be-extinction) context, there was evidence for impaired extinction (i.e., state splitting or more discrimination).

Finally, it is worth noting that there are fundamental similarities between the effects of extinction training shortly after fear conditioning and the effects of this extinction training shortly after fear memory retrieval. The procedure used by Monfils et al.
(2009), Schiller et al. (2010) and here is very similar to that first developed by Myers et al. (2006) to study the effects of immediate vs. delayed extinction. The only substantive difference is whether extinction training occurs after conditioning (e.g., Myers et al. 2006) or after memory retrieval (Monfils et al. 2009; Schiller et al. 2010). Inconsistent results have been reported regarding the effects of immediate vs. delayed extinction training after conditioning. Immediate extinction training after conditioning can reduce (e.g., Myers et al. 2006) or augment later fear recovery (e.g., Maren and Chang 2006). Likewise, immediate extinction training after memory retrieval can reduce (e.g., Monfils et al. 2009; Schiller et al. 2010) or augment (the present experiments) later fear recovery. These contrasting results do not reduce the theoretical and practical significance of demonstrations of impaired fear recovery after immediate extinction. Rather, they underscore the need for further research in this area.

In summary, we studied the influence of a recent exposure to a fear CS on later extinction of that CS. The results showed that these exposures augmented recovery, as measured by renewal and reinstatement, of extinguished fear. These results stand in contrast to those reported by Monfils et al. (2009) as well as Schiller et al. (2010). We suggest that these contrasting effects can be understood as either due to the contrasting influences on extinction learning of different associations formed during presentations of the CS in the retrieval phase of the experiment or due to differences in discrimination between conditioning and extinction promoting differences in the amount of unlearning during extinction.

\section{Materials and Methods}

\section{Subjects}

The subjects were experimentally naïve, adult male Wistar rats obtained from a commercial supplier (Monash Animal Services, Victoria, Australia). There were 16 rats per experiment $(n=8)$ except Experiment 4B, which used 12 rats. Upon arrival, rats were housed in groups of eight in plastic cages $(67 \mathrm{~cm}$ long $\times$ $30 \mathrm{~cm}$ wide $\times 22 \mathrm{~cm}$ high) in a colony room maintained at $20^{\circ} \mathrm{C}-22^{\circ} \mathrm{C}$ on a $12-\mathrm{h} / 12$-h light/dark cycle (lights on at 07:00 h). Food and water were freely available. The rats were handled (1-2 min per rat per day) for $3 \mathrm{~d}$ prior to conditioning to habituate them to the experimenter. The procedures used in this and following experiments were conducted in accordance with the New South Wales Government Animal Research Regulation 1995 and were approved by the Animal Care and Ethics Committee of the University of New South Wales.

\section{Apparatus}

\section{Experiments $1,2 A, 2 B$, and 3}

Conditioning and testing were conducted in two different sets of chambers located in different rooms. The first set (context A) consisted of four identical chambers $(20.4 \mathrm{~cm}$ long $\times 23.4 \mathrm{~cm}$ wide $\times$ $19.5 \mathrm{~cm}$ high). The front, rear, and side walls and the hinged lid of these chambers were made of clear Perspex. The floor in each chamber consisted of stainless steel rods $4 \mathrm{~mm}$ in diameter spaced $15 \mathrm{~mm}$ apart (center to center). Each chamber stood $3.5 \mathrm{~cm}$ above a tray of paper pellet bedding (Fibrecycle). The chambers were cleaned with alcohol, and bedding was changed between rats. These chambers were located individually within sound-attenuating boxes, the inner walls of which were painted black. The boxes were illuminated with a white 24 -V light. An extractor fan in the rear wall of each box was operating during all sessions providing a constant background noise ( $67 \mathrm{db}$; A scale).

The second set (context B) consisted of another four identical chambers $(24 \mathrm{~cm}$ long $\times 30 \mathrm{~cm}$ wide $\times 21 \mathrm{~cm}$ high). The top and rear walls of these chambers and the front hinged door were constructed of clear Perspex, and the end walls were made of stainless 
steel. An additional Perspex board served as the floor. Each chamber stood $2 \mathrm{~cm}$ above a tray of corn bedding (Fibercycle) into which was placed $1 \mathrm{~mL}$ of dilute peppermint oil. The chambers were cleaned with alcohol, and the bedding underneath the chambers was changed between rats. These four chambers were located individually within sound-attenuating boxes that were painted white. The boxes were constantly illuminated by a single red LED such that levels of illumination within the conditioning chambers were 15 candela $/ \mathrm{m} 2$. Ventilation fans provided a constant background noise (67 dB; A scale).

Like Monfils et al. (2009), these chambers were not counterbalanced to serve as the training and extinction contexts. The absence of such counterbalancing makes inferences about context specificity difficult (Lovibond et al. 1984), but we adopted this approach because it was precisely that approach used by Monfils et al. (2009).

The CS was a 20-sec, 750-Hz, 90-dB (A scale) tone, delivered through a speaker mounted on the ceiling of each sound-attenuating box. The footshock US was a 0.5-sec, 0.7-mA, unscrambled AC $50-\mathrm{Hz}$ shock from a constant current generator that was delivered to the floor of each chamber. The current available to each floor could be adjusted using an in-line milliampere meter. Digital video cameras were mounted on the rear wall of each box and connected to a digital multiplexer in an adjacent room that, in turn, was connected to a DVD recorder. The stimuli used for conditioning were controlled by computer (LabView, National Instruments).

\section{Experiments $4 A$ and $4 B$}

The apparatus described as context $\mathrm{B}$ for experiment 1 was used as the single context in experiment $4 \mathrm{~A}$. For experiment $4 \mathrm{~B}$, a different set of four chambers was used. Each chamber measured $30 \mathrm{~cm}$ high $\times 27 \mathrm{~cm}$ long $\times 30 \mathrm{~cm}$ wide. The sidewalls and ceiling were made of aluminum, and the back and front walls were made of clear plastic. The sidewalls and ceiling were painted black. The floor consisted of stainless steel rods, $2 \mathrm{~mm}$ in diameter, spaced $10 \mathrm{~mm}$ apart, center to center, with a tray below containing bedding material. Each chamber was enclosed in a sound- and lightattenuating shell. Illumination for each chamber was provided by an infrared light source $(940 \pm 25 \mathrm{~nm})$. The inside walls of the shells were painted black. A white fluorescent tube and a speaker mounted on the back wall of each shell were used, respectively, for the presentation of a 30-sec light CS (approximately 57 lux measured at the center of the chamber) flashing at a rate of three per second during the otherwise dark session and a $30-\mathrm{sec}, 1-\mathrm{kHz}$ sine wave tone CS with a rise/fall of $10 \mathrm{msec}$ measuring $70 \mathrm{~dB}$ (A scale) against a background noise of $\approx 40 \mathrm{~dB}$ measured by a digital sound level meter (Dick Smith Electronics). The physical identity of the two CSs was fully counterbalanced. A custom-built constant-current shock generator, capable of delivering unscrambled AC $50-\mathrm{Hz}$ shock to the floor of each chamber, was used for the presentation of a 0.5-mA, 0.5-sec shock US. A camera mounted on the back wall of each shell was used to record the behavior of each rat. Each camera was connected to a monitor and a DVD recorder located in another room of the laboratory. This room contained the computer that controlled stimulus presentations via appropriate software (LabView).

\section{Behavioral procedures}

\section{Experiment 1}

Fear acquisition. On day 1, rats were placed in the experimental chamber (context A). After a 10-min adaptation period, the CS was presented for $20 \mathrm{sec}$. The shock US was administered during the last half a second of the CS presentation. A further two CS-US pairings were presented, with an intertrial interval (ITI) of 3 min.

Retrieval. On day 2, rats were allocated into one of the two groups: group Retrieval (Ret) $(n=8)$ or group No Retrieval (No Ret) $(n=8)$. In this and subsequent experiments, group allocation was random. Group Ret was placed into context B. After a 3-min adaptation period, a nonreinforced CS was presented for $20 \mathrm{sec}$. Rats were removed from the chambers after another 100 sec. Group No Ret did not receive a retrieval trial but were only exposed to context B for $5 \mathrm{~min}$. Both groups were then returned to their home cages.

Extinction. Ninety minutes after the end of the retrieval phase, all rats were returned to context B for a 62 -min, 20-sec session. There was a 2-min adaptation period followed by 18 (group Ret) or 19 (group No Ret) 20-sec presentations of the nonreinforced $\mathrm{CS}$ at an ITI of $3 \mathrm{~min}$. Group Ret was left in the chambers for $3 \mathrm{~min}, 20 \mathrm{sec}$ before being removed following the 18th CS presentation. Group No Ret was removed from the chambers immediately after the 19 th CS presentation. Thus, the two groups were matched in the amount of exposure to the nonreinforced CS, and to the extinction context (context B) on day 2.

Test in extinction context. On day 3, all animals were returned to the extinction chambers (context B) and tested. There was a 2-min adaptation period followed by four nonreinforced presentations of the CS. The ITI was 2 min.

Test in acquisition context. On day 4 , all animals were returned to the fear conditioning chambers (context A) and tested. The procedures on this test were identical to that of the previous test.

\section{Experiments $2 A$ and $2 B$}

All behavioral procedures were identical to experiment 1 with the single exception that retrieval occurred in context A (Experiment $2 \mathrm{~A}$ ) or context B (Experiment $2 \mathrm{~B}$ ).

\section{Experiment 3}

All behavioral procedures were identical to experiment 1 with the single exception that the interval between retrieval and extinction was 10 min.

\section{Experiment $4 A$}

Fear acquisition. On day 1 , the procedures were identical to those of experiment 1 with the only exception that the CS was of 30-sec duration.

Retrieval. On day 2, rats were allocated to one of two groups: group Ret $(n=8)$ or group No Ret $(n=8)$. The procedures were identical to those in the previous experiments with two exceptions. First, the nonreinforced CS was presented in the context for $30 \mathrm{sec}$. Second, rats were removed from the chambers $90 \mathrm{sec}$ after the retrieval trial.

Extinction. Ten minutes after the end of the retrieval phase, all rats were returned to the chambers for a 29-min, 30-sec session. There was a 2-min adaptation period followed by 18 (group Ret) or 19 (group No Ret) 30-sec presentations of the nonreinforced $\mathrm{CS}$ at an ITI of $1 \mathrm{~min}$. Group Ret was left in the chambers for $1 \mathrm{~min}, 30 \mathrm{sec}$ before being removed following the 18th CS presentation. Group No Ret was removed from the chambers immediately after the 19th CS presentation. Thus, the two groups were matched in the amount of exposure to the nonreinforced CS and to the extinction context (context B) on day 2.

Reinstatement. On day 3, both groups were returned to the chambers for a 10-min session, during which two unsignaled shocks $(0.7 \mathrm{~mA}, 0.5 \mathrm{sec})$ were administered at the third and eighth minute, respectively. 
Test. On day 4, all animals were returned to the chambers and tested. There was a 2-min adaptation period followed by four nonreinforced presentations of the 30 -sec CS. The ITI was $1 \mathrm{~min}$.

\section{Experiment $4 B$}

Pre-exposure. On days 1 and 2, rats received twice daily (a.m. and p.m.) 30-min exposures to the chambers. On day 3, rats were briefly familiarized with the light and tone stimuli to ensure perceptual discrimination between the CSs. In each of the a.m. and p.m. sessions, each stimulus was presented on four occasions in an intermixed, pseudo-random order with the constraint that the same stimulus could not occur on more than two consecutive presentations. The pseudo-random order of these presentations was determined anew after every four rats in each counterbalancing condition. The average trial position for the two CSs was balanced across the session. The interval between each stimulus presentation, defined as stimulus offset to stimulus onset, was $3 \mathrm{~min}$, and the duration of each stimulus presentation was $30 \mathrm{sec}$. After the final stimulus presentation, rats remained in the chamber for a further $2 \mathrm{~min}$ before they were returned to their home cage.

Conditioning. On day 4, rats were given four conditioning trials to each of the two CSs. The procedure for conditioning was that used in pre-exposure except that each presentation of a CS coterminated with a shock US that was $0.5-\mathrm{mA}$ intensity and 0.5-sec duration.

Retrieval. On day 5, rats were given a single nonreinforced exposure to one of the two CSs (designated A) 2 min after placement in the chambers at a duration of $30 \mathrm{sec}$. After this CS presentation, rats remained in the chambers for a further $2 \mathrm{~min}$ before they were returned to their home cages.

Extinction. Ten minutes after the retrieval session, rats were extinguished over 20 nonreinforced trials to CSA and 21 nonreinforced trials to the other CS (designated B) in an intermixed, pseudorandom order described for pre-exposure and conditioning. The CS presentations began 2 min after placement in the chambers. The interval between each CS presentation (CS offset-CS onset) was $1 \mathrm{~min}$. The duration of each CS presentation was $30 \mathrm{sec}$. After the final CS presentation, rats remained in the chamber for a further $2 \mathrm{~min}$ before they were returned to their home cages. The data from one rat during extinction training were lost to a failure of the video recording apparatus.

Reinstatement. Two days after the extinction session, rats were returned to the chambers and subjected to a single shock $(0.5 \mathrm{~mA}, 0.5 \mathrm{sec}) 5 \mathrm{~min}$ later. Rats remained in the chambers for an additional $5 \mathrm{~min}$ before they were returned to their home cage.

Test. On the following day, rats were tested for responding to both CSs in a single session. The first CS presentation occurred $2 \mathrm{~min}$ after exposure to the chambers. Each CS was presented four times in an intermixed, pseudo-random order described above. The average trial position for the two CSs was balanced across the session. The interval between CS presentations was 2 min, and the duration of each presentation was $30 \mathrm{sec}$. After the final CS presentation, rats remained in the chambers for 2 min before they were returned to their home cages.

\section{Data analysis}

Rats were scored every $2 \mathrm{sec}$ as either freezing (defined as the absence of all movement other than that required for breathing) or not freezing during each stage of the experiments. The number of observations scored as freezing during each observation period was summed and converted to a percentage. Test data were scored by two observers. The inter-rater reliability, that is, the correlation between the percentages of observations each rat was scored as freezing by each observer, ranged from $0.85-0.96$ across experiments. The differences between groups were analyzed by means of a planned orthogonal contrast testing procedure, whereas the within-session changes of responding were assessed by a planned linear trend analysis. The Type I error rate was controlled at 0.05 for each contrast tested.

\section{Acknowledgments}

We thank Rick Richardson for helpful discussions of these experiments. This research was supported by an Australian Postgraduate Award to W.Y.M.C. and by grants from the Australian Research Council to G.P.M. (DP0877430) and from the National Health and Medical Research Council to R.F.W. (455319). G.P.M. is an Australian Research Council QEII Research Fellow (DP0877430).

\section{References}

Bouton ME. 1993. Context, time, and memory retrieval in the interference paradigms of Pavlovian learning. Psychol Bull 114: 80-99.

Bouton ME. 2002. Context, ambiguity, and unlearning: Sources of relapse after behavioral extinction. Biol Psychiatry 52: 976-986.

Bouton ME, Bolles RC. 1979. Contextual control of the extinction of conditioned fear. Learn Motivat 10: 445-466.

Capaldi EJ. 1966. Partial reinforcement: A hypothesis of sequential effects. Psychol Rev 73: 459-477.

Chelonis JJ, Calton JL, Hart JA, Schachtman TR. 1999. Attenuation of the renewal effect by extinction in multiple contexts. Learn Motivat 30: $1-14$.

Delamater AR. 2004. Experimental extinction in Pavlovian conditioning: Behavioural and neuroscience perspectives. Q J Exp Psychol B 57: 97-132.

Garfield JB, McNally GP. 2009. The effects of FG7142 on overexpectation of Pavlovian fear conditioning. Behav Neurosci 123: 75-85.

Gunther LM, Denniston JC, Miller RR. 1998. Conducting exposure treatment in multiple contexts can prevent relapse. Behav Res Ther 36: $75-91$.

Harris JA, Jones ML, Bailey GK, Westbrook RF. 2000. Contextual control over conditioned responding in an extinction paradigm. J Exp Psychol Anim Behav Process 26: 174-185.

Leung HT, Westbrook RF. 2008. Spontaneous recovery of extinguished fear responses deepens their extinction: A role for error-correction mechanisms. J Exp Psychol Anim Behav Process 34: 461-474.

Lovibond PF, Preston GC, Mackintosh NJ. 1984. Context specificity of conditioning, extinction, and latent inhibition. J Exp Psychol Anim Behav Process 10: $360-375$.

Maren S, Chang CH. 2006. Recent fear is resistant to extinction. Proc Natl Acad Sci 103: $18020-18025$.

Monfils MH, Cowansage KK, Klann E, LeDoux JE. 2009. Extinctionreconsolidation boundaries: Key to persistent attenuation of fear memories. Science 324: 951-955.

Myers KM, Ressler KJ, Davis M. 2006. Different mechanisms of fear extinction dependent on length of time since fear acquisition. Learn Mem 13: 216-223.

Pavlov IP. 1927. Conditioned reflexes. Oxford University Press, Oxford, UK.

Redish AD, Jensen S, Johnson A, Kurth-Nelson Z. 2007. Reconciling reinforcement learning models with behavioral extinction and renewal: Implications for addiction, relapse, and problem gambling. Psychol Rev 114: 784-805.

Rescorla RA. 2001. Experimental extinction. In Handbook of contemporary learning theories (ed. RR Mowrer, SBL Klein), pp. 119-154. Erlbaum Associates Publishers, Mahwah, NJ.

Rescorla RA. 2006a. Spontaneous recovery from overexpectation. Learn Behav 34: 13-20.

Rescorla RA. 2006b. Deepened extinction from compound stimulus presentation. J Exp Psychol Anim Behav Process 32: 135-144.

Rescorla RA, Heth CD. 1975. Reinstatement of fear to an extinguished conditioned stimulus. J Exp Psychol Anim Behav Process 1: 88-96.

Robbins SJ. 1990. Mechanisms underlying spontaneous recovery in autoshaping. J Exp Psychol 16: 235-249.

Schiller D, Monfils MH, Raio CM, Johnson DC, Ledoux JE, Phelps EA. 2010. Preventing the return of fear in humans using reconsolidation update mechanisms. Nature 463: 49-53.

Storsve AB, McNally GP, Richardson R. 2010. US habituation, like CS extinction, produces a decrement in conditioned fear responding that 
is NMDA dependent and subject to renewal and reinstatement. Neurobiol Learn Mem 93: 463-471.

Urcelay GP, Lipatova O, Miller RR. 2009. Constraints on enhanced extinction resulting from extinction treatment in the presence of an added excitor. Learn Motiv 40: 343-363.

Wagner AR. 1976. Priming in STM: An information processing mechanism for self-generated or retrieval-generated depression in performance. In Habituation: Perspectives from child development, animal behavior and neurophysiology (ed. TJ Tighe, RN Leaton), pp. 95-128. Erlbaum, Hillsdale, NJ.
Wagner AR. 1981. SOP: A model of automatic memory processing in animal behavior. In Information processing in animals: Memory mechanisms (ed. NE Spears, RR Miller), pp. 5-47. Erlbaum, Hillsdale, NJ.

Westbrook RF, Iordanova M, McNally G, Richardson R, Harris JA. 2002. Reinstatement of fear to an extinguished conditioned stimulus: Two roles for context. J Exp Psychol Anim Behav Process 28: 97-110.

Received June 17, 2010; accepted in revised form August 3, 2010. 


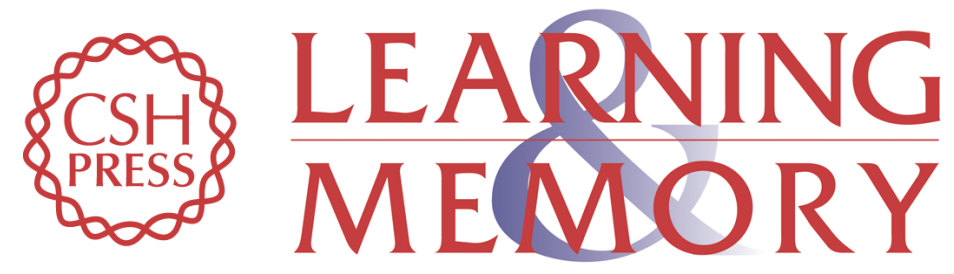

\section{Effects of recent exposure to a conditioned stimulus on extinction of Pavlovian fear conditioning}

Wan Yee Macy Chan, Hiu T. Leung, R. Frederick Westbrook, et al.

Learn. Mem. 2010, 17:

Access the most recent version at doi:10.1101//m.1912510

References This article cites 23 articles, 3 of which can be accessed free at:

http://learnmem.cshlp.org/content/17/10/512.full.html\#ref-list-1

License

Email Alerting Receive free email alerts when new articles cite this article - sign up in the box at the Service top right corner of the article or click here. 